\title{
PERCEPTIONS AND ABILITIES RELATED TO PATIENT ENGAGEMENT IN DIABETES CARE AMONG PRIMARY HEALTHCARE PROVIDERS IN MALAYSIA: A QUALITATIVE STUDY
}

\author{
Karoline Kragelund Nielsen [Kragelund Nielsen K] ${ }^{1}$, Michael Calopietro [Calopietro M] ${ }^{1}$, Toh Peng Yeow \\ [Yeow TP] ${ }^{2}$, Tahir bin Aris [Tahir A] ${ }^{3}$ and Ulla Bjerre-Christensen [Bjerre-Christensen U] ${ }^{1}$ \\ ${ }^{1}$ Steno Diabetes Center Copenhagen, Niels Steensens Vej 2-4, 2820 Gentofte, Denmark. \\ 2 Penang Medical College, Jalan Sepoy Lines, 10450 Penang, Malaysia. \\ 3Institute of Public Health, Ministry of Health, Jalan Bangsar, 50590 Kuala Lumpur, Malaysia..
}

Corresponding author: Karoline Kragelund Nielsen

Email: karoline.kragelund.nielsen@regionh.dk.

\begin{abstract}
Malaysia seeks to transform its public healthcare sector to manage the growing number of people with diabetes. Patient engagement is a critical clinical competency for healthcare providers treating people with diabetes. In this study, we investigate the perceptions of and ability to practice patient engagement among doctors and nurses working in Malaysia's primary healthcare system. Semi-structured interviews were conducted with nine non-specialist doctors and ten nurses working in primary healthcare clinics. Further, 12 key informants with specialist knowledge about diabetes care and the healthcare system in Malaysia were interviewed. The interviews were analyzed using qualitative content analysis. Three main themes emerged: 1) understanding barriers to self-care and treatment, 2) perceived training needs and skills within patient engagement and empowerment, and 3) challenges to the practice of patient engagement. A range of barriers was identified in healthcare providers' ability to practice patient engagement. Future efforts should seek to improve competencies within patient engagement, identification of especially psychosocial barriers to self-care and empowerment. Yet, available manpower and time also influence whether patient engagement is practiced.
\end{abstract}

Keywords: Diabetes, patient engagement, Malaysia, educational needs assessment, barriers to self-care.

\section{INTRODUCTION}

Most low and middle-income countries are facing an increasing number of people with diabetes 1 and many are insufficiently prepared to detect and manage the condition in primary care settings 2 , 3. Life with diabetes requires a large degree of self-management 4,5 . Therefore, people with diabetes are expected to take more responsibility for their health and healthcare, requiring a high degree of patient empowerment. The ability to facilitate such empowerment and to engage in shared decision making is a critical clinical competency for healthcare providers 6 . Patient empowerment and engagement involves care that is personalized and enabling. This means care that is guided by the needs, values and preferences of the patient and which takes into account the barriers and enablers to self-care and treatment experienced by the person with diabetes 7-9.

Malaysia has an estimated diabetes prevalence rate of $16.8 \%{ }^{1}$. However, the public primary healthcare system has largely been oriented towards the management of acute conditions, and not towards chronic conditions such as diabetes ${ }^{10,11}$. With the epidemiological transition, the primary health care system increasingly has to be geared to handle the current and future number of diabetes patients ${ }^{10-12}$. This requires, among other things, an adequate number of well-trained healthcare providers.

The Ministry of Health in Malaysia is trying to address the current treatment gaps and their most recent health sector strategic plans call for health sector transformation via a more efficient delivery of services, human capital development, and diabetes care of international quality ${ }^{13}$. Furthermore, the Ministry of Health is currently collaborating with Steno Diabetes Centre Copenhagen in Denmark to provide a competency-based diabetes educational program that seeks to improve the knowledge, attitudes and skills of primary care doctors and nurses. This study aimed to identify diabetes-specific clinical competencies in need of strengthening, including perceptions of and ability to practice patient engagement among Malaysian primary healthcare providers. 


\section{METHODS}

\section{Design}

A qualitative research approach using in-depth interviews was selected for this study. The qualitative data were triangulated across the dimensions of space/geography (different health centers in three different states) and persons (doctors, nurses and key informants).

\section{Study settings and data collection}

The data collection was conducted between September and December 2014 in three states purposively selected to represent a diversity of geography and levels of urbanization: W.P. Kuala Lumpur (urban), Kedah (peri-urban), and Sarawak (rural). Within each State, three to four public health sector clinics were chosen randomly. All interviews were conducted by trained qualitative researchers in either Bahasa Malaysia or English.

\section{In-depth interviews with healthcare providers}

Semi-structured in-depth interviews were conducted with non-specialist doctors and nurses selected by convenience. Interviews with one doctor and one nurse at each clinic were attempted, but not fully achieved. Consequently, a total of nine doctors and ten nurses from ten different clinics were interviewed. An overview of the participating healthcare providers is given in Table 1. Separate interview guides were used for doctors and nurses. Questions focused on the participant's experience with diabetes education, clinical experience and diabetes care.

\section{[Table 1 Characteristics of study participants]}

\section{Key Informant Interviews}

Semi-structured interviews were conducted with 12 key informants, who were purposively selected for their specialist knowledge about diabetes care and the healthcare system in Malaysia. Key informants included endocrinologists, Family Medicine Specialists, and leading diabetes educators working in the public healthcare system, as well as leaders and representatives from the Ministry of Health, professional diabetes associations, and Malaysian medical schools, nursing schools and other training programs.

\section{Data Analysis}

All interviews were audio-recorded and transcribed in full length. If they were conducted in Bahasa Malaysia they were subsequently translated into English. The analysis followed the process of thematic content analysis ${ }^{14}$ with the coding of the data being a combination of inductive and a priori coding. The latter focuses on core concepts and constructs within patient empowerment such as shared decision making, personalized care and barriers to self-care and treatment. The software program NVivo 10 (QSR International Pty Ltd. 1999-2012) was used to perform the coding and organize the data.

\section{Ethical considerations}

Before the interview, the participants were informed about the background of the interviewer and the educational program; that participation in the interview was voluntary; and that their replies and identity would be anonymous. To protect the identity of the participants, each was assigned an identification number and the names of people and places below the State level have been removed from the excerpts. Permission to audio record the interview was obtained and an informed consent form available in both English and Bahasa Malaysia was signed. Ethical approval for the study was granted by the Medical Research and Ethics Committee of Malaysia (NMRR-14-100421981).

\section{RESULTS}

Three main themes emerged from the analysis: 1 ) understanding barriers to self-care and treatment, 2) perceived training needs and skills within patient engagement, and 3) challenges to the practice of patient engagement.

\section{Understanding barriers to self-care and treatment}

It was evident that the interviewed healthcare providers were aware that patients experience barriers to self-care and challenges in the following treatment. It was also recognized that some patients have difficulties following lifestyle advice. However, this was largely attributed to patient attitudes. Some healthcare providers complained about patients not taking their condition and the associated risks seriously, and articulated difficulties in changing attitudes and motivating people with diabetes to modify behaviour.

'I don't know what skill to handle their [the patients'] attitude even though l've been here for 10 years now. It isn't easy to change anyone, but it's tough when the patient refuses to change despite your countless attempts in advising them.... They don't comply with dietary requirements. It's all about the attitude. A good attitude ensures good control. I don't know about other places, but here the attitude is a real challenge for us to change. I have no clue as to what it takes to change their attitudes'. (Nurse 2, from Kedah).

The lack of adherence to treatment and a profound fatalistic attitude to self-care among some patients frustrated the healthcare providers who felt the patients were 'wasting everyone's time'. But while the healthcare providers 
expressed frustration with the lack of adherence, it was not clear whether such frustrations were accompanied by investigations into the underlying barriers faced by the person with diabetes. There were healthcare providers who noted they never really asked their patients about the reasons for such non-adherence. The issue of non-adherence to pharmacological therapy and healthcare providers' ability to deal with this was also mentioned by key informants as an area for further training. The healthcare providers did identify certain barriers to self-care in the interviews, including low socio-economic position, cost of care, lack of social support, being afraid of needles and misconceptions about diabetes. Yet, it was evident that in clinical care the focus tends to be on control of the clinical markers; and efforts to understand the patient's situation could be enhanced.

In particular, shortcomings related to understanding psychosocial aspects were mentioned. This was also strongly emphasized by several key informants.

'What I think is underdone is the psychosocial aspect. Probably not looked into by the doctor. Not listened to very much by the other members of the healthcare team. So, management is still very much glucose-centric. Not asking how they feel unless they tell us they're feeling unwell. So depression and psychosocial impact of disease on the patient and the family should be looked into'. (Key Informant - Endocrinologist)

Perceved training needs and skills within patient engagement

The data suggest a substantial variation in the healthcare providers' approaches to and skills in patient engagement, as well as the perceptions of the need for improvement. In the interviews with some key informants it was stressed that there is an overall need for further training related to engaging and empowering the patients:

'When it comes to supporting patients, who selfmanage, I think there is still much to be strengthened in terms of empowering the patient. I think that's where the education needs should come in, because there must be skills of how do you engage the patient, how do you empower them, and how do you change the behavior?' (Key Informant - Medical School Educator).

When asked directly, some healthcare providers, especially nurses without diabetes training, but also some doctors, were unfamiliar with concepts such as empowerment, personalized care, and motivational interviewing. On the other hand, a few healthcare providers - the nurses who had participated in extensive training on diabetes care in particular - emphasized the importance of building rapport and engaging the patients, particularly about understanding underlying causes of non-adherence. The discrepancy may rest on the interpretations of what these concepts mean. Thus, although some healthcare providers indicated attempts to individualize care by considering the patient's daily routine, work-life, etc. when making recommendations, the involvement of the patient in these decisions and considerations were generally not articulated. Even among some of the key informants, who called for improvements in terms of individualizing lifestyle advice, what was articulated is personalization without real patient engagement as suggested by this quote:

'Example: this patient cannot exercise because of a very bad knee. So how are you gonna do it? You cannot be telling this woman 'you must do 150 minutes of exercise per week; you must, regardless of your knee'. You cannot. You have to say 'ok, your knee is a problem. Then we will teach you static exercise - strengthening exercise - you can do at home'. So these are the skills that I want them [the healthcare providers] to learn.' (Key Informant - Physician)

It is about tailoring care to the individual, but do so by the healthcare provider, not necessarily in collaboration with the patient. Hence, the data suggest that current practice largely relies on a 'teach and tell' approach, rather than collaborating with the person with diabetes. This was also noted by some key informants and both doctors and nurses acknowledged the need to improve their own patient engagement skills and expressed an interest in further training.

'I've never had any formal training on this, but I think this is something that I would like to learn. Something that I would like to have as one of my extra skills, because I think it's very, very important to connect with the patient. I think the success of the treatment depends on how well you are connecting with your patient. We may give treatment, but whether the patient will comply with the treatment depends on how well we have connected with the patient or how well they have actually understood why this particular doctor has given me this'. (Doctor 7, from Sarawak).

\section{Challengesb to the practice of patient engagement}

The data show that certain issues within the healthcare system influence whether healthcare providers are able to practice patient engagement. Especially challenges with staffing and time were repeatedly brought up by the informants. The ratio of patients to healthcare providers means that healthcare providers find 
themselves faced with limited time per patient. Nurses reported having around 10-15 minutes with each patient. Doctors reported substantially less time - around five minutes. Consequently, there is not enough time to cover all the relevant aspects in detail, carry out the examinations, and answer the patients' questions. The healthcare providers expressed difficulties in spending the necessary time to understand the barriers faced by the patient and to conduct personalized, patient-centered care

'The other thing is that for personalized care we need more doctors because we are short of doctors - short of staff and the support staff like the dietician. We have one dietician. I think that is not enough. We need more to actually give counseling to all the diabetes patients'. (Doctor 6, from Kuala Lumpur).

On the other hand, citing lack of time as a reason for not conducting proper care was considered 'an excuse' by some key informants.

'You don't need to do a lot. If you have let's say twenty or forty patients, you just select two you will cover. Later on when they come to see you again for the next appointment, you choose another one. So slowly you will empower the patients'. (Key Informant - Physician).

Moreover, while acknowledging that time was limited, key informants also noted that training might improve the use of that time.

' think it is an excuse. Even if it is a short time, I think you can zoom in on the key problem and address that. But it is training. It is a skill.... I agree that they are very busy; especially when they are not competent in a sort of discussing more complex issues.... The challenge is to develop a program that addresses this. You have ten minutes how do I maximize you to use the ten minutes? How do I train you to be competent within that ten minutes?' (Key Informant Medical School Educator).

\section{DISCUSSION}

In this study, we have investigated perceptions of and ability to practice patient engagement among healthcare providers working in primary care within the public healthcare sector in Malaysia. We identified three main themes: understanding barriers to self-care and treatment; perceived training needs and skills within patient engagement; and challenges to the practice of patient engagement.
Anumber of studies have investigated related aspects of diabetes care and self-management in Malaysia, especially exploring barriers to self-care and treatment among people with diabetes 15-19. These studies highlight a lack of knowledge, impact of family relationships, concerns about adverse effects of treatment, and financial barriers. However, to the best of our knowledge, this is the first study to explore perceptions and skills within patient engagement related to diabetes care among healthcare providers in Malaysia. The findings of our study suggest shortcomings related to placing the patient at the center of all therapeutic decisions and in personalizing care. Although largely focused on the attitude of the patients, the healthcare providers described a range of potential barriers to self-care and treatment such as socio-economic position; lack of social support; and misconceptions and lack of knowledge. Thus, our findings confirm and transcend the finding of previous studies.

We found that the barriers and resulting low adherence to the prescribed treatment were articulated as being a great frustration to the healthcare providers. Especially psychosocial barriers were emphasized as being unaddressed and unattended to by the healthcare providers in our study. Psychosocial barriers to metabolic control have been identified and investigated in studies by Loke \& Jong (2008), and Tong et al (2015), with the latter authors calling for healthcare providers to address these through individualized plans, attention to patients' selfefficacy, misconceptions and psychological and emotional problems 20, 21. Further, the importance of this issue was also highlighted in a recent study showing high prevalence rates of depression, anxiety and stress symptoms among type 2 diabetes patients in Malaysia 22

The findings highlight that there are challenges with available manpower and time, and that these influence whether the healthcare providers are able to carry out the patient engagement. In their study on barriers to insulin initiation, Lee et al (2012) similarly identified a lack of manpower as a key barrier within the public healthcare system, noting that there were far too few trained diabetes educators and dieticians to handle the heavy patient loads ${ }^{18}$. Hence, the findings of our study and others' suggest efforts are needed to enhance healthcare providers' understanding of the patient's situation. Further strengthening of skills within patient empowerment in general, and patient engagement in particular is also needed. The focus appears to be on a 'teach and tell' approach rather than more inclusive care with 
a focus on collaboration and empowerment. Finally, it is evident that while the identified challenges may be improved through training programs, improved knowledge will hold limited value if the clinical context offers little opportunity to demonstrate new skills. Other efforts will be needed to address these challenges to patient empowerment.

Qualitative research is used to study a specific phenomenon in a specific context, and the generalizability of the findings to settings outside Malaysia may, therefore, be doubtful. On the other hand, studies from other countries have reported similar results ${ }^{23-28}$, and our findings may have applicability or at least relevance to other settings as well, especially other middle-income countries seeking to tackle the growing number of people with diabetes. Moreover, while our focus here has been on diabetes care, it is likely that some of our findings may also have relevance to other chronic diseases addressed in the primary healthcare sector.

There is a risk that the background of the interviewers and the project may have introduced courtesy bias or social-desirability bias, i.e. the informants give the answers they think is the 'correct answer' or the answer that the interviewer wants to hear 29,30 . In order to minimize such responses, the interviewers emphasized that the purpose of the interview was not a test of knowledge or competencies when introducing the study and this was repeated

during the interviews themselves. The main strength of this study is that by combining data from different settings and data from doctors, nurses and key informants a more comprehensive and holistic understanding of the patient engagement related experiences, perceptions and skills among healthcare providers could be achieved. In the sampling of health centers it was sought to ensure maximum variation in terms of states and levels of urbanization, which was done to ensure diversity and thereby get as many nuances and different perspectives as possible ${ }^{31}$, 32.

\section{CONCLUSION}

In this study, we have investigated Malaysian healthcare providers' perceptions of and ability to practice patient engagement related to diabetes management. Various shortcomings related to patient engagement and understanding barriers to self-care, as well as issues, which influence whether healthcare providers are able to carry out patient engagement, were identified. Future training and capacity building efforts should seek to improve competencies within patient engagement, identification of especially psychosocial barriers to self-care and empowerment. Yet, other efforts are also needed to address the factors in the clinical context, which may hamper the opportunity of healthcare providers to practice these skills.

\section{ACKNOWLEDGEMENTS}

The authors wish to thank the Malaysian Ministry of Health, particularly the Director General for his permission to publish this paper and Datuk Dr. Lokman Hakim Sulaiman, Deputy Director General of Health (Public Health) for providing the financial support from Public Health Program for the educational programme. From the IKU Institute of Public Health, we especially wish to thank Dr. Normawati Binti Ahmad for her role in organising and facilitating the study. Thank you also to Dr. Jeshen Lau and Dr. K. H. Chang for helping and providing valuable inputs to the data collection and verification. The authors would like to thank the Novo Nordisk Foundation for funding the program. Finally, the authors would like to thank Dr. Jens Aagaard-Hansen for his insightful comments to an earlier version of the manuscript.

\section{COMPETING INTEREST}

UB-C holds stocks in Novo Nordisk A/S. At the time of the research and writing of the manuscript $M C$ was employed at Steno Diabetes Center. He is currently employed at Novo Nordisk A/S. KKN, TPY and TA declare no individual conflicts of interest.

\section{FUNDING}

The study was funded by a grant from the Novo Nordisk Foundation. The funding body did not have any role in the study design, data collection, data analysis and interpretation, writing the manuscript or in the decision to publish the manuscript.

\section{Ethics approval and consent to participate}

Written informed consent to participate and permission to audio record the interview was obtained from all participants. Ethical approval for the study was granted by the Medical Research and Ethics Committee of Malaysia (NMRR-14-100421981). 


\section{Availability of data and materials}

Data is not publicly available. The study uses qualitative data, and making the data publicly available would hamper participant privacy and anonymity.

Authers'contributions

MC, TPY, AT, UB-C conceived the study design and contributed to the data acquisition. KKN

Table 1: Characteristics of study participants performed the data analysis with substantial inputs from MC and TPY. KKN wrote the first draft of the manuscript. All authors critically revised the manuscript for intellectual content and approved the final version of the manuscript

\begin{tabular}{llll}
\hline \multicolumn{2}{c}{ Profession } & $\begin{array}{l}\text { Geographical } \\
\text { region }\end{array}$ & Past training attended on diabetes \\
\hline Doctors & & \\
\hline 1 & Doctor & Kedah & Limited Short Format \\
2 & Doctor & Kedah & Limited Short Format \\
3 & Doctor & Kedah & Limited Short Format \\
4 & Doctor & Kuala Lumpur & None \\
5 & Doctor & Kuala Lumpur & None \\
6 & Doctor & Kuala Lumpur & Limited Short Format \\
7 & Doctor & Sarawak & Limited Short Format \\
8 & Doctor & Sarawak & Limited Short Format \\
9 & Doctor & Sarawak & Limited Short Format \\
Nurses & Kedah & Extensive \\
1 & Diabetes Educator & Kedah & Diabetes educator course, post basic diabetes course \\
2 & Diabetes Specialist & Kedlat & \\
& Nurse & Kedah & Extensive \\
3 & Diabetes Educator & Kuala Lumpur & None \\
4 & Nurse & Kuala Lumpur & Limited Short Format \\
5 & Senior Nurse & Kuala Lumpur & None \\
6 & Community Nurse & Kuala Lumpur & Extensive \\
7 & Senior Nurse & Sarawak & None \\
8 & Nurse & Sarawak & Limited Short Format \\
9 & Nurse & Sarawak & None \\
10 & Nurse & \multicolumn{3}{l}{} \\
\hline
\end{tabular}

\section{REFERENCES}

1. International Diabetes Federation. IDF Diabetes Atlas 9th Edition Brussels, Belgium2019.

2. Lall D, Prabhakaran D. Organization of primary health care for diabetes and hypertension in high, low and middle income countries. Expert Rev Cardiovasc Ther. 2014; 12:987-95..

3. Samb B, Desai N, Nishtar S, Mendis S, Bekedam $\mathrm{H}$, Wright $\mathrm{A}$, et al. Prevention and management of chronic disease: a litmus test for health-systems strengthening in lowincome and middle-income countries. Lancet. 2010; 376:1785-97.
4. Brown SA. Studies of educational interventions and outcomes in diabetic adults: a meta-analysis revisited. Patient Educ Couns. 1990; 16:189-215.

5. Rubin RR, Peyrot M, Saudek CD. Effect of diabetes education on self-care, metabolic control, and emotional well-being. Diabetes Care. 1989; 12:673-9.

6. Glasgow RE, Hiss RG, Anderson RM, Friedman NM, Hayward RA, Marrero DG, et al. Report of the health care delivery work group: behavioral research related to the establishment of a chronic disease model for 
diabetes care. Diabetes Care. 2001; 24:124-30.

7. Fisher L, Mullan JT, Arean P, Glasgow RE, Hessler D, Masharani U. Diabetes distress but not clinical depression or depressive symptoms is associated with glycemic control in both crosssectional and longitudinal analyses. Diabetes Care. 2010; 33:23-8.

8. Gonzalez JS, Safren SA, Cagliero E, Wexler DJ, Delahanty L, Wittenberg $E$, et al. Depression, self-care, and medication adherence in type 2 diabetes: relationships across the full range of symptom severity. Diabetes Care. 2007; 30:2222-7.

9. The Health Foundation. Personcentred care made simple. London2014.

10. Ramli A, Taher S. Managing chronic diseases in the malaysian primary health care - a need for change. Malays Fam Physician. 2008; 3:7-13.

11. Ariffin F, Ramli AS, Daud MH, Haniff J, Abdul-Razak S, Selvarajah S, et al. Feasibility of Implementing Chronic Care Model in the Malaysian Public Primary Care Setting. Med J Malaysia. 2017; 72:106-12.

12. Ambigga KS, Ramli AS, Suthahar A, Tauhid N, Clearihan L, Browning C. Bridging the gap in ageing: Translating policies into practice in Malaysian Primary Care. Asia Pac Fam Med. 2011; 10:2.

13. Ministry of Health Malaysia. Country Health Plan: 10th Malaysia Plan 20112015. Putrajaya: Kementerian Kesihatan Malaysia; 2010.

14. Graneheim UH, Lundman B. Qualitative content analysis in nursing research: concepts, procedures and measures to achieve trustworthiness. Nurse Educ Today. 2004; 24:105-12.

15. Abu Hassan $\mathrm{H}$, Tohid $\mathrm{H}$, Mohd Amin $\mathrm{R}$, Long Bidin MB, Muthupalaniappen $\mathrm{L}$, Omar K. Factors influencing insulin acceptance among type 2 diabetes mellitus patients in a primary care clinic: a qualitative exploration. BMC Fam Pract. 2013; 14:164.
16. Al-Qazaz H, Sulaiman SA, Hassali MA, Shafie AA, Sundram $S$, Al-Nuri R, et al. Diabetes knowledge, medication adherence and glycemic control among patients with type 2 diabetes. Int J Clin Pharm. 2011; 33:1028-35.

17. Al-Qazaz HK, Hassali MA, Shafie AA, Syed Sulaiman SA, Sundram S. Perception and knowledge of patients with type 2 diabetes in Malaysia about their disease and medication: a qualitative study. Res Social Adm Pharm. 2011; 7:180-91.

18. Lee YK, Lee PY, Ng CJ. A qualitative study on healthcare professionals' perceived barriers to insulin initiation in a multi-ethnic population. BMC Fam Pract. 2012; 13:28.

19. Tan WL, Asahar SF, Harun NL. Insulin therapy refusal among type II diabetes mellitus patients in Kubang Pasu district, the state of Kedah, Malaysia. Singapore Med J. 2015; 56:224-7.

20. Loke SC, Jong M. Metabolic control in type 2 diabetes correlates weakly with patient adherence to oral hypoglycaemic treatment. Ann Acad Med Singapore. 2008; 37:15-20.

21. Tong WT, Vethakkan SR, Ng CJ. Why do some people with type 2 diabetes who are using insulin have poor glycaemic control? A qualitative study. BMJ Open. 2015; 5:e006407.

22. Kaur G, Tee GH, Ariaratnam S, Krishnapillai AS, China K. Depression, anxiety and stress symptoms among diabetics in Malaysia: a cross sectional study in an urban primary care setting. BMC Fam Pract. 2013; 14:69.

23. Fort MP, Alvarado-Molina N, Pena L, Mendoza Montano C, Murrillo S, Martinez $\mathrm{H}$. Barriers and facilitating factors for disease self-management: a qualitative analysis of perceptions of patients receiving care for type 2 diabetes and/or hypertension in San Jose, Costa Rica and Tuxtla Gutierrez, Mexico. BMC Fam Pract. 2013; 14:131.

24. Fritz H, DiZazzo-Miller R, Bertran EA, Pociask FD, Tarakji S, Arnetz J, et al. Diabetes self-management among Arab Americans: patient and provider 
perspectives. BMC Int Health Hum Rights. 2016; 16:22.

25. Jeragh-Alhaddad FB, Waheedi $M$, Barber ND, Brock TP. Barriers to medication taking among Kuwaiti patients with type 2 diabetes: a qualitative study. Patient Prefer Adherence. 2015; 9:1491-503.

26. Schulman-Green D, Jaser SS, Park C, Whittemore R. A metasynthesis of factors affecting self-management of chronic illness. J Adv Nurs. 2016; 72:1469-89.

27. Shen $H$, Edwards $H$, Courtney $M$, McDowell J, Wei J. Barriers and facilitators to diabetes selfmanagement: perspectives of older community dwellers and health professionals in China. Int $J$ Nurs Pract. 2013; 19:627-35.

28. Stuckey $\mathrm{HL}$, Vallis $M$, Kovacs Burns $\mathrm{K}$, Mullan-Jensen CB, Reading JM, Kalra $S$, et al. "I Do My Best To Listen to Patients": Qualitative Insights Into DAWN2 (Diabetes Psychosocial Care From the Perspective of Health Care Professionals in the Second Diabetes Attitudes, Wishes and Needs Study). Clin Ther. 2015; 37:1986-98 e12.

29. Blum F. Getting Individuals to Give Information to the Outsider. Journal of Social Issues. 1952; 8:8.

30. Jones E. The Courtesy Bias in SouthEast Asian Surveys. In: Bulmer $M$, Warwick D, editors. Social Research in Developing Countries: Surveys and Censuses in the Third World. London: Routledge; 1983.

31. Christensen U, Schmidt L, Dyhr L. The qualitative research interview. In: Vallgårda S, Koch L, editors. Research methods in public health. Copenhagen: Gyldendal Akademisk; 2008.

32. Hardon A, Boonmongkon P, Streefland P, Tan ML. Applied Health Research Manual: Anthropology of Health and Health Care: Transaction Publishers; 2001. 